\title{
Uma política para a pesquisa educacional no Brasil
}

Jayme Abreu

Palavras-chave: pesquisa educacional; práxis pedagógica; Brasil.
* Publicado originalmentena Revista Brasileira de Estudos Pedagógicos, v. 52, n. 115, p. 6-12 jul./.set., 1969, seção: Editorial.
Ao tentar formular diretrizes para uma política de pesquisa educacional no Brasil, é preciso partirmos de certas formulações preliminares, indispensáveis à colocacão do tema.

\section{A débil incorporação do método científico à praxis escolar}

Como premissa de caráter básico é necessário convir-se que no campo da educação escolar não se tem assinalado o mesmo grau de incorporação do comportamento científico assinalado, por exemplo, nos domínios da Física, da Química, da Biologia ou nas ciências aplicadas, como a Medicina ou Engenharia.

Em verdade, costume e tradição, autoridade, experiência pessoal e raciocínio silogístico continuam ainda prevalecendo no campo educacional, com lenta e parcimoniosa introdução do inquérito ou pesquisa científica em suas práticas.

Há mesmo quem questione sobre a viabilidade da aplicação sistemática de métodos científicos no campo da educação, entendida esta como o conhecimento sistematizado da acão ou processo de educar. A inviabilidade ou, pelo menos, a dificuldade estaria na instabilidade das variáveis do sistema encarado, não comparável com o que ocorre no campo das ciências físico-naturais; por isso que, nesse campo da educação, seus processos são fixados em função de valores finais estabelecidos pela sociedade, não pela ciência e sim por princípios morais ou religiosos, elaborados por processos filosóficos ou especulativos, não classificáveis como processos científicos.

\section{Variações de conceituação de pesquisa educacional}

Na conceituação do que se deva entender como pesquisa educacional, podem ser assinaladas posições metodológicas não coincidentes.

Na primeira Conferência Internacional de Pesquisa Educacional, realizada em Atlantic City, em fevereiro de 1956, o professor Erich Hylla, diretor emérito do Instituto Internacional de Pesquisa Educacional (Frankfurt, Alemanha), apresentou estudo sobre "A natureza e as funções da pesquisa educacional", no qual identifica dois grandes tipos de pesquisa educacional:

a) pesquisas estritamente experimentais ou científicas, com o uso de experiências, de raciocínios indutivos, de verificação por meio de novas experiências, de resultados obtidos em cada fase de trabalho, de medidas, de métodos estatísticos e de observações tão objetivas quanto possível;

b) pesquisas filosóficas, como seriam aquelas no campo da educação comparada, da história da educação, da administração escolar, etc., jogando basicamente com raciocínios especulativos e dedutivos sobre valores.

Na mesma Conferência, o ponto de vista que se poderia chamar de norte-americano a respeito do conceito de pesquisa educacional é definido no relatório apresentado pelo 
professor Francis Cornell, presidente da American Educational Research Association.

Segundo esse ponto de vista, a pesquisa seria - lato sensu - a atividade de coletar informações (ou observar a realidade) de modo ordenado e sistemático, de maneira a chegar a normas sistemáticas de ação racional. Uma amplitude de concepção bem mais elástica quanto ao campo e menos rígida metodologicamente do que a germânica (de Erich Hylla).

A posição inglesa na conceituação de pesquisa educacional e de pesquisa científica em educação, tal como a define Ben Morris, ${ }^{1}$ é intermediária entre a alemã (segundo Hylla) e a norte-americana (segundo Cornell).

Assim se manifesta Morris:

No sentido mais alto, a pesquisa é apenas uma forma de reflexão crítica sobre a experiência, incluindo a busca (e respectiva interpretação) do que é novel na experiência; a pesquisa educacional é mais considerada como a aplicação desse ângulo crítico ao estudo profissional da educação.

Pesquisa educacional, portanto, aparece aqui como um termo amplo que abriga não só experiências destinadas a descobrir novos fatos ou as relações entre os fatos, mas incluindo também as atividades escolásticas, históricas ou filosóficas que, embora possam conduzir à descoberta de novos fatos ou à redescoberta de fatos velhos, se aplicam freqüentemente à reinterpretação de fatos já bem conhecidos.

Os fascínios exercidos pelas técnicas quantitativas resultaram, nos últimos tempos, em estreitamento de visão na pesquisa e no crescimento de rigidez, dentro do próprio movimento científico. Criou-se, assim, uma atmosfera inimiga tanto da especulação quanto da reflexão crítica.

Conseqüentemente, a pesquisa padece da falta de um tipo de orientação que só o pensamento crítico pode oferecer, tendendo a identificar-se com uma parte instumental de si mesma e correndo, com isso, o perigo de degenerar numa tecnologia.

É verdade que o trabalho especulativo prossegue, mas há quase completa ausência de esforços no sentido de vincular o ângulo experimental ao corpo geral da teoria educativa e vice-versa.
A nosso entendimento, essa posição metodológica de Ben Morris expressa concepção de inteira pertinência quanto à necessidade de vinculação orgânica entre o "ângulo factual e experiencial" e o "corpo geral da teoria educativa", o que realmente representa uma premência a ser alcançada pelos sistemas educativos do mundo, nas relações entre a pesquisa, a teoria educacional e a praxis escolar.

\section{Situação da pesquisa educacional na América Latina}

Em estudo recente (novembro, 1967) de autoria de Pablo Cetapi e Hernán Vera, elaborado para a OEA sob o título A prestação de serviços de assistência técnica em matéria de pesquisa, experimentação e inovação educacional e para o aperfeiçoamento de pessoal especializado", se define como pesquisa educacional

[...] a busca sistemática e metodológica dos problemas intrínsecos aos processos educativos e às iniciativas, estruturas e organizações que têm por fim a educação [...] O objetivo do método científico tem sido sempre organizar o conhecimento humano em forma sistemática, estabelecendo sua validade em princípios e fórmulas de caráter geral.

Como áreas para a pesquisa educacional, o estudo em questão assim as resume:

1. Desenvolver uma teoria mais adequada e válida sobre os processos educativos em si mesmos e suas relações sobre o funcionamento dos organismos que têm por fim a educação. É efetivamente a teoria que faz mais compreensível a realidade, a meta básica de toda pesquisa.

2. Elaborar um corpo de informações acerca da educação, útil para tomar decisões e modelar políticas. O conhecimento de dados e suas relações permite prever o comportamento futuro dos acontecimentos e, dentro de certa medida, alterá-los.

3. Elaborar sistemas e procedimentos de avaliação dos resultados educativos conseguidos mediante uso de determinados meios e circunstâncias.

4. Proporcionar estímulo e orientação para as inovações educacionais. Como demonstra a história da educação e a analogia com a agricultura, a medicina e a

\footnotetext{
MORRIS, Ben J. A pesquisa educacional na Inglaterra e no País de Gales. Internacional Review of Education, v. 1, n. 1, 1955.
} 
indústria, as inovações provêm sempre de novos conhecimentos que são fruto da pesquisa.

No documento em questão, seus autores dão um balanço bastante fiel da situação da pesquisa educacional na América Latina, o qual transcrevemos a seguir:

Nos países latino-americanos não há uma tradição própria e sólida de pesquisa educacional. Os atuais esforços são heterogêneos em seus temas, unilaterais em seu enfoque e, de modo geral, de muito diverso valor em sua metodologia. A predominância dos temas psicopedagógicos, devido sobretudo à influência francesa e norte-americana, deixou de ser tão absoluta em conseqüência do recente interesse pelo planejamento educacional. A atenção ao planejamento educacional trouxe como conseqüência um enriquecimento da pesquisa educacional com novos métodos e novos enfoques de disciplinas.

Todavia não se pode dizer que a pesquisa educacional na América Latina seja uma realidade consistente em si mesma, integrada e adaptada à problemática que deve resolver.

\section{Sugestões para uma política de pesquisa educacional no Brasil}

Feita esta parte introdutória, pela qual se resume o que é escassez de incorporação do método científico ao trato corrente dos problemas educacionais, as diferenças conceituais no entendimento do que é pesquisa educacional, e uma apreciação a largos traços da situação da pesquisa educacional na América Latina, passamos a tentar esboçar algumas sugestões sobre o que seria uma política de pesquisa educacional para o Brasil, isto é, recomendações sobre os critérios e objetivos a adotar para a implantação dessa política no País.

\section{Escolha de problemas a pesquisar}

Acreditamos que as recomendações emergentes dos três grupos de trabalho em que se dividiu a Conferência de Pesquisa Educacional de Atlantic City, sobre escolha de problemas a pesquisar, continuam inteiramente válidas e abrangem os seguintes aspectos para a escolha desses problemas a pesquisar:

a) sua relevância direta e prática dentro do sistema educacional estudado;

b) que se prestem a pesquisas imediatas, ou através de amostragem ou do "estudo de caso";

c) que sejam limitados em seus objetivos e na extensão, com referência aos recursos humanos e materiais;

d) que sejam imperiosas, seja por suas conseqüências imediatas ou de mais longo alcance.

Como situações que se podem lembrar, entre nós, enquadradas nessa problemática educacional, podem ser lembradas, ao lado de outras, aquelas relativas à administração das escolas e dos sistemas de ensino, aos métodos e às técnicas de ensino, à elaboração curricular e sua adequação ao ambiente, à análise dos manuais escolares e dos conteúdos de programas de ensino, aos critérios de promoção, ao estudo da evasão escolar, à formação profissional e ao treinamento em serviço dos profissionais da educação, ao nível econômico, social e cultural de docentes e discentes, ao balanço crítico da adequação e da extensão das oportunidades educacionais ensejadas e que devam ser ensejadas, etc.

Na realização dessas pesquisas, de acordo ainda com recomendação emanada da Conferência de Atlantic City, é preciso ter sempre em vista "evitar escolher projetos de pesquisa triviais ou inexeqüíveis" e alcançar "a elevação do nível de pesquisa educacional e revisão de sua estrutura teórica para aumento de sua eficácia, seja na seleção dos problemas, no rigor metodológico e na apresentação das observações e conclusões que não devem nunca levar à desorientação dos que as consomem".

Como tipos de organização própria à realização da pesquisa educacional, podem citar-se:
a) universidades;
b) órgãos governamentais;
c) entidades públicas autônomas;
d) associações voluntárias da classe;
e) empresas privadas.

No que concerne ao problema fundamental da seleção, preparação e treinamento de pesquisadores educacionais, o assunto reclama um desenvolvimento que não pode caber 
nos limites deste artigo, exigindo abordagem específica.

Como exemplo típico da formulação de um plano de pesquisas para órgãos de âmbito nacional, como é o caso do Inep, a nós se afigura que nenhum documento é mais expressivo, em termos brasileiros, do que aquele que foi elaborado quando da criação do Centro Brasileiro e dos Centros Regionais de Pesquisa Educacional do Inep, os quais teriam, sem dúvida, atingido seus fins na medida em que tivessem realizado a pesquisa educacional necessária à consecução destes objetivos:

a) pesquisa das condições culturais e escolares e das tendências de desenvolvimento de cada região e da sociedade brasileira como um todo, para o efeito de elaboração gradual de uma política educacional para o País;

b) elaboração de planos, recomendações e sugestões para a revisão e a reconstrução educacional do País em cada região - nos níveis primário, médio e superior e no setor de educação de adultos;

c) elaboração de livros-fonte e livrostexto, de material de ensino e estudos especiais sobre administração escolar, construção de currículos, psicologia educacional, filosofia da educação, medidas escolares, preparo de mestres, etc., a fim de propiciar o aperfeiçoamento do magistério nacional;

d) treinamento e aperfeiçoamento de administradores escolares, orientadores educacionais, especialistas em educação, professores de escolas normais e professores primários.
Se alguma coisa pudéssemos sugerir em aditamento às pesquisas educacionais implícitas ao desenvolvimento do plano de ação dos Centros, seria ela a da realização de pesquisas sistemáticas, periódicas, regulares, dos custos e de produtividade dos sistemas de ensino do País. Igualmente uma sugestão que não podemos deixar de fazer é a da realização, preliminar e necessária às pesquisas propriamente ditas, dos grandes levantamentos macroscópicos no País, de estatística demográfica e educacional, de finanças em geral e da educação, de legislação e administração escolar, etc.

Sem eles, sem a realização dessa tão modesta quão indispensável tarefa, será quase estulto pensar na realização de pesquisas educacionais mais sofisticadas ou requintadas. A falta deles constitui o desespero de quantos se lançam a essa área de estudos, ensejando inclusive apreciações desprimorosas, mas verdadeiras, de peritos estrangeiros, ao se surpreenderem com a falta de disponibilidade desses dados básicos, fidedignos, em muito maior escala no Brasil do que ocorre, por exemplo, com países africanos.

Na medida em que os órgãos responsáveis pela pesquisa educacional no Brasil tomassem como ponto de referência, para orientação de sua política quanto à pesquisa educacional a realizarem, aquelas condensadas e expressivas recomendações da $1^{\mathrm{a}}$ Conferência Internacional de Pesquisa Educacional, teríamos, sem dúvida, os fundamentos para uma racional e operativa política de pesquisa educacional no Brasil, com as opções de temas que emanassem dos aspectos nacional e regional da educação nesse país-continente que é o Brasil.

Jayme Abreu (16/2/1909-23/2/1973) foi diretor da Divisão de Estudos e Pesquisas Educacionais do Centro Brasileiro de Pesquisas Educacionais (CBPE) do Inep de 1957 a 1973. 